\title{
Critérios de textualidade do gênero gráfico: a interdisciplinaridade como fator para a compreensão textual
}

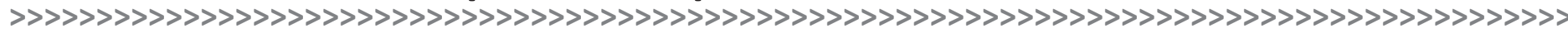

\author{
Priscila Cruz de Sousa*
}

\section{Resumo:}

O artigo em questão analisa os gráficos matemáticos a partir da sua presença ou ausência² em atividades dos livros didáticos de Ensino Fundamental de 3ㅇ e 5ㅇano, compreendendo as seguintes disciplinas escolares: Ciências, Geografia, História, Língua Portuguesa e Matemática. Valendo-nos de uma concepção interacional e dialógica da língua (BAKHTIN, 2003, p. 277-289), pretendemos oferecer subsídios para o que postulamos: o gráfico ${ }^{3} \mathrm{Como} \mathrm{um}$ texto e ferramenta interdisciplinar ${ }^{4}$ que articula as diversas áreas do saber e que, ainda, devido à sua circulação ampla em diferentes suportes, pode ser comum no dia a dia dos alunos. Para o desenvolver deste trabalho, partimos da observação de que a condução das atividades propostas em livros didáticos é ineficiente para o desenvolvimento de uma compreensão leitora crítica; condução que na maioria das vezes, se não todas, propõe atividades sob o ponto de vista da literalidade.

\section{Palavras-chave:}

Compreensão leitora. Interdisciplinaridade. Gênero textual. Gráficos. Livro didático.

\begin{abstract}
:
This article analyzes the graphics parting from its presence or absence in the activities of basic education textbooks of $3^{\text {rd }}$ and $5^{\text {th }}$ grade comprising the following school subjects: Science, Geography, History, Portuguese Language and Mathematics. Drawing on an interactive and dialogical conception of language (BAKHTIN, 2003, p. 277-289), we aim to offer subsidies to what we postulate: the graph as a text and interdisciplinary tool that articulates the various areas of knowledge and also due to its wide circulation on different media may be common in the daily life of students. To develop this work, we start from the observation that the driving conducing to the proposed activities in textbooks is inefficient for the development of a critical reading comprehension, most, if not all, propose activities from the point of view of literalness.
\end{abstract}

\section{Keywords:}

Reading comprehension. Interdisciplinarity. Textual genre. Graphics. Textbook.

,

* > Graduanda do Curso de Letras/Português na Universidade Federal do Piauí-UFPI. E-mail: priscilasousa2@homail.com.

$2>$ Analisamos a ausência como um princípio regulador para os dados, na medida em que o gráfico nos interessa como mais um gênero a ser inserido como ferramenta importante que sumariza informações e que funciona como elo entre diferentes disciplinas no contexto escolar.

3 > Termo que será ampliado nesta pesquisa, mas que enfatizamos, por ora, conforme Rocha (2005, p. 359), expressar a "representação de um fenômeno qualquer através de coordenadas, barras ou setores".

4 > Sem nos aprofundarmos no debate, nossa discussão, ao tempo que retrata as disciplinas escolares, está centrada na proposta de interdisciplinaridade escolar. Tanto as disciplinas quanto a interdisciplinaridade escolar são tomadas em suas diferenças em relação às disciplinas e à interdisciplinaridade científica. (Leonoir, 1998). 


\section{Introdução}

Desencadeadores da comunicação social, os gêneros do discurso, conceituados como "formas relativamente estáveis de enunciados" (BAKHTIN, 2003, p. 261-262), têm crescente alteração, complementação e criação justificadas pelo dinamismo próprio da linguagem em interação, conforme interlocutores e contextos históricos e socioculturais. As práticas de linguagem realizam-se por meio de gêneros. Desse modo, é imprescindível que o sujeito saiba como essa comunicação funciona e de que modo as interaçães influenciam no processo de criação e de estabilização dos gêneros do discurso.

Alguns critérios são postulados para a definição dos gêneros do discurso, tais como: estilo, forma, composição, conteúdo e suas peculiaridades reconhecidas pela comunidade linguística, tal como postula Bakhtin:

O emprego da língua efetua-se em forma de enunciados (orais e escritos) concretos e únicos, proferidos pelos integrantes desse ou daquele campo da atividade humana. Esses enunciados refletem as condições específicas e as finalidades de cada referido campo não só por seu conteúdo (temático) e pelo estilo da linguagem, ou seja, pela seleção dos recursos lexicais, fraseológicos e gramaticais da língua mas, acima de tudo, por sua construção composicional. Todos esses três elementos - o conteúdo temático, o estilo, a construção composicional - estão indissoluvelmente ligados no todo do enunciado e são igualmente determinados pelas especificidades de um determinado campo da comunicação. Evidentemente, cada enunciado particular é individual, mas cada campo de utilização da língua elabora seus tipos relativamente estáveis de enunciados, os quais denominamos gêneros do discurso (BAKHTIN, 2003, p. 262).

Posto isso, na perspectiva de gênero como inerente às práticas comunicativas, temos o gráfico e sua larga escala de utilização cotidiana. Apresentando pouca visibilidade na esfera escolar como um texto para ser estudado no modismo do ensino conforme os PCNs, percebemos que o gráfico não é tratado como um texto, mas como uma figura, por vezes, um diagrama ou, até mesmo, uma gravura.

Figurantes, sobretudo, na educação matemática, conforme abordaremos ao longo deste artigo, os gráficos geralmente são definidos como recursos representativos de dados estatísticos que possibilitam ao leitor uma visualização sumária de informações. Em meio a isso, podemos encontrar, porém, o gráfico aliado aos conceitos de linguagem gráfica ${ }^{5}$, tal como pontua Klüsener:

Uma forma de comunicação vivenciada por todos, no nosso cotidiano, é a da linguagem gráfica ${ }^{6}$, que é expressa através de tabelas, diagramas e esboços. Com esta linguagem é possível traduzir situações nas mais diferentes áreas do conhecimento, possibilitando a interpretação e a análise crítica de dados, entre outros (KLÜSENER, 2000 apud NEVES et al., 2007, p. 186).

É valido ressaltar que as abordagens do gráfico na esfera escolar nos oportunizam tornar notáveis os vários tratamentos a ele atribuídos. Nas concepções da Língua Portuguesa, a guisa de exemplo, os gráficos são tratados com estatuto de complemento a um segundo texto que possam acompanhá-lo. É factível verificar, entretanto, que a análise e interpretação do gráfico contempla um caráter didático e autônomo, de tal forma que é exequível ao aluno a compreensão de informações expostas, confrontando tal associação de suplementação.

Argumentamos, ainda, que alguns tipos de gráficos, apesar de associarem-se a outro texto, possuem uma natureza independente, para a qual se (re)constrói uma interpretação, que, além de ser uma sumarização do conteúdo informacional do texto, ao qual ele é associado, é, acima de tudo, uma proposta de atribuição de sentidos. 
Nosso referencial teórico compreende não só o gráfico como uma apresentação de dados sobre uma realidade descrita e pontual (TOLEDO, 1985, p. 75-78), porque depende de uma situação real, estando sua interpretação e compreensão condicionada, inclusive, às vivências e particularidades de cada leitor, mas também como um projeto de dizer $(\mathrm{KOCH}$, 2012, p. 36), pois os gráficos contemplam propósitos de comunicação social, permitindo ao leitor, portanto, a realização de inferências.

O modo como é instigada a compreensão textual do gráfico demanda um amplo estudo, pois, mediante sondagem nos livros didáticos, constatamos que o aluno é levado a apenas verificar fatos, apontar dados, não os questionando ou os criticando.

Com efeito, é proveitoso o desenvolvimento e a prática de estratégias que permitam ao leitor a compreensão do texto gráfico, de modo que o aluno seja instigado a uma meditação pós-interpretação, visto que o sujeito enquanto ser social precisa acima de tudo compreender os dados expostos, a fim de que consiga utilizar tais conhecimentos adquiridos em várias outras situações. Dessa maneira, sintetizamos a carência no que concerne à metodologia de ensino e aprendizagem dos gráficos no que diz respeito ao ato de ler e compreender o texto.

Sustentamos, aqui, a leitura como uma rede de subordinações e de permanentes reconstruções, na qual autor e texto devem estar intimamente relacionados com o intuito de encadear o leitor, para que se entusiasme a conferir seus significados ao texto produzido. Sob esse enfoque, corrobora Kehrwald (2000, p. 21 apud NEVES et al., 2007, p. 24): "Ler, portanto, não é tentar decifrar ou adivinhar de forma isenta o sentido de um texto, mas é, a partir do texto, atribuir-lhe significados relacionando-o com outros textos na busca da sua compreensão, dos seus sentidos e de outras possíveis leituras.”

\section{Revisão de literatura: o gráfico como objeto de estudo}

Mesmo que ainda incipiente no Brasil, a literatura sobre a concepção do gráfico enquanto texto vem ganhando formas nas áreas científicas. Entretanto, as pesquisas existentes o analisam em interação com um texto base, sendo poucos os trabalhos que apresentam o estudo do texto gráfico em suas particularidades.

Duarte (2008), em suas observações, analisou 45 sujeitos que realizaram a leitura de gráficos isolados e integrados ao gênero notícia, com o intuito de verificar divergências, ou não, na interpretação do leitor, relacionadas ao modo como o texto se fez presente, e de constatar em quais habilidades o leitor apresenta(ria) maior desempenho. Como parte da metodologia de pesquisa utilizada pela autora, os sujeitos foram levados a responder 24 questões a respeito das habilidades envolvidas na leitura do gráfico nas duas formas em que foi apresentado. Em termos de resultados, foi constatado que a compreensão do gráfico foi mais relevante quando apresentado junto a outro texto, ao gênero notícia, no caso. A habilidade com maior sucesso foi a de "[...] reconhecer os referentes dos elementos gráficos” (p. 04); a de insucesso foi “[...] inferir o tema de um texto” (p. 04).

Para o trabalho a que nos propomos, é interessante ressaltar que, mesmo abordando o gráfico interligado a outros textos, a autora acima citada o defende como gênero textual: "Trata-se de um gênero textual, de fato, pois gêneros textuais podem se apresentar em interação num suporte, referindo ao mesmo ser ou objeto no mundo". (DUARTE, 2008, p. 19).

Monteiro (1999) também utilizou o gráfico como objeto de estudo, analisando-o pedagogicamente. Através de contextualizações históricas, o autor discorre de modo argumentativo sobre a importância do gráfico no ensino escolar, na mídia impressa, e sobre seu funcionamento na interação social. 
Diferentemente de Duarte (2008), constatamos que Monteiro (op.cit.) se detém à análise do gráfico apenas como um instrumento ilustrativo, tal como ainda postulam as ciências exatas.

Paula (2010) corroborou também essas discussões. Utilizando como aporte os três momentos envolvidos na realização da leitura dos gráficos, que são: antes, durante e depois da leitura (SOLÉ, 1998, p. 89). A autora também sugere a aplicação das estratégias que são utilizadas na leitura de textos narrativos em textos gráficos. Os estudos da autora supracitada têm como enfoque alunos do $5^{\circ}$ ano do Ensino Fundamental.

A pesquisa à qual nos dedicamos analisará o gráfico enquanto texto e, portanto, como possibilitador de eventos comunicativos, ao tempo em que apresentará estratégias metacognitivas interdisciplinares a serem utilizadas e/ou ensinadas para o processamento da leitura de textos gráficos.

\section{Metodologia}

Para desenvolvermos o estudo, identificamos, no Guia de Livros Didáticos - PNLD 2013-2015, os títulos indicados para os $3^{\circ}$ e $5^{\circ}$ anos do Ensino Fundamental compreendendo as disciplinas escolares. Partimos da escolha pela análise do Guia de Livros Didáticos PNLD 2013, pois ele nos permite o acesso a informações úteis para a escolha de livros qualificados em âmbito escolar. O processo da pesquisa envolve as seguintes etapas: (1) verificação dos livros por áreas do saber; (2) identificação da presença do gráfico nas coleções de livros didáticos indicados pelo PNLD e sua incidência nesses materiais por área; (3) abordagem metodológica e; (4) o estudo do gráfico enfatizando seu caráter de textualidade, o processamento e a compreensão leitora.

Ao final da pesquisa, pretendemos estabelecer um perfil da presença do gráfico como objeto de ensino e de aprendizagem, evidenciando o seu funcionamento discursivo realizado de forma interdisciplinar.

\section{Resultados e análises}

\section{O processamento do gráfico antes, durante e após a leitura: conhecimentos ativados pelo leitor}

Dia a dia, nós nos deparamos com textos de diversos tipos e variados gêneros e, devido aos conhecimentos por nós adquiridos, conseguimos distingui-los em suas peculiaridades. Os gráficos, por exemplo, possuem propriedades que permitem ao leitor classificá-los como tal. Essa classificação tem como base, dentre inúmeros aspectos, a composição, o conteúdo temático e o estilo próprio de cada texto (BAKHTIN, 2003, p. 280).

Conhecemos a composição, o conteúdo temático e o estilo predominante nos gêneros devido nossa "competência metagenérica" (KOCH, 2012, p. 112). É essa competência a responsável por guardar a vivência que o sujeito adquire constantemente no contato com cada tipo de texto, os quais exigem interpretações e estratégias únicas.

Antes da leitura (SOLÉ, 1998, p. 70-75), reconhecendo o texto gráfico e seus consecutivos propósitos textuais, quais sejam, informar de modo antes visual do que verbal, o sujeito, num primeiro momento, tem seu olhar estagnado, ou sua percepção ativada, 
para aquilo que lhe chama atenção; seja pelo fato de o assunto ser considerado atrativo, ou pelo suporte em que se encontra, ou pelo interesse no gênero em questão, ou ainda por outros variados motivos.

Diante de textos gráficos, numa perspectiva leitora, o sujeito prontifica-se a dar continuidade à sua leitura, devido aos evidenciados elementos presentes no texto, tais como; as cores quentes, os desenhos (no caso de infográficos), o título, que composto de poucas palavras em negrito ou itálico já engloba inúmeras leituras, ou a fonte em tamanho ampliado, que formam a estrutura do gráfico, tal como podemos analisar a partir da figura 1 a seguir:

Figura 1 - Projeto Ápis, Ciências, 5ano.

\section{GRÁFICOA}

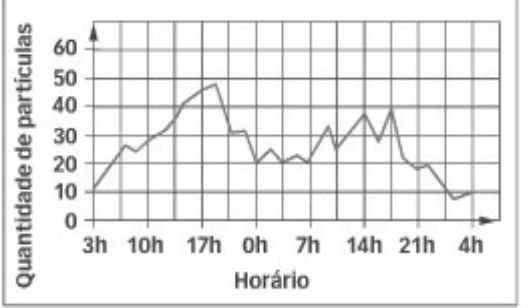

Analise os gráficos e responda às perguntas:

a) A que horas costumam ocorrer picos no tráfego de veículos?

No periodo da tarde, por volta das 14h-15h, costumam ocorrer os picos do número de vefculos que trategam na rodovia.

b) E a que horas costumam ocorrer picos nos níveis de partículas no ar, que podemos respirar e que podem fazer mal à nossa saúde? No mesmo perfodo da tarde costumam ocorrer os picos nos niveis de particulas no at.

c) Praticamente năn nassam veícılıs na rndnvia em nı ıe horárin?

Fonte: Projeto Ápis (Editora Ática, 2013, p. 198)

Ao analisar a figura anterior, o leitor, primeiramente, tem como elemento retentor de sua atenção as linhas que compõem o gráfico. Coloridas, elas podem fazer alusão às linhas do monitor de frequência cardíaca, por exemplo. Essa "lembrança”, ou seja, esse conhecimento ativado, diz respeito ao conhecimento de mundo que tem o leitor ( $\mathrm{KOCH}$, 2011, p. 24). Se a vivência do sujeito o permitiu algum tipo de contato com o instrumento utilizado para monitorar a frequência cardíaca, é provável que seu cérebro faça a imediata associação. E, mesmo que esse gráfico não esteja de acordo com o que o leitor previu, as associações prévias, conceituadas como "Procedimento, com frequência chamado também de regra, técnica, método, destreza ou habilidade, é um conjunto de ações ordenadas e finalizadas dirigidas à consecução de uma meta" (COLL, 1987, p. 89 apud SOLÉ, 1998, p. 68), serão de inteira importância, na medida em que estimularão o interesse do leitor em buscar alicerces que constatem ou refutem tais previsões. Nessa mesma linha de pensamento, pontua Smith:

A previsão é o núcleo da leitura. Todos os esquemas, scripts e cenários que temos em nossas cabeças - nosso conhecimento prévio de lugares e situações, de discurso escrito, gêneros e histórias - possibilitam-nos prever quando lemos, e assim, compreender, experimentar e desfrutar do que lemos. A previsão traz um significado potencial para os textos, reduz a ambiguidade e elimina, de antemão, alternativas irrelevantes (SMITH, 2003, p. 34). 
A partir das previsões e das inferências, a leitura será iniciada de modo a atingir expectativas. Podemos, pois, dizer que o leitor entrará num processo de busca pela significação ou coerência do texto. Na próxima figura, a Figura 2, observaremos a ativação dos conhecimentos por parte do leitor:

\section{Figura 2 - A escola é nossa Ciências 50 ano.}

2. Depois, ela construiu um gráfico* de colunas com os resultados obtidos.
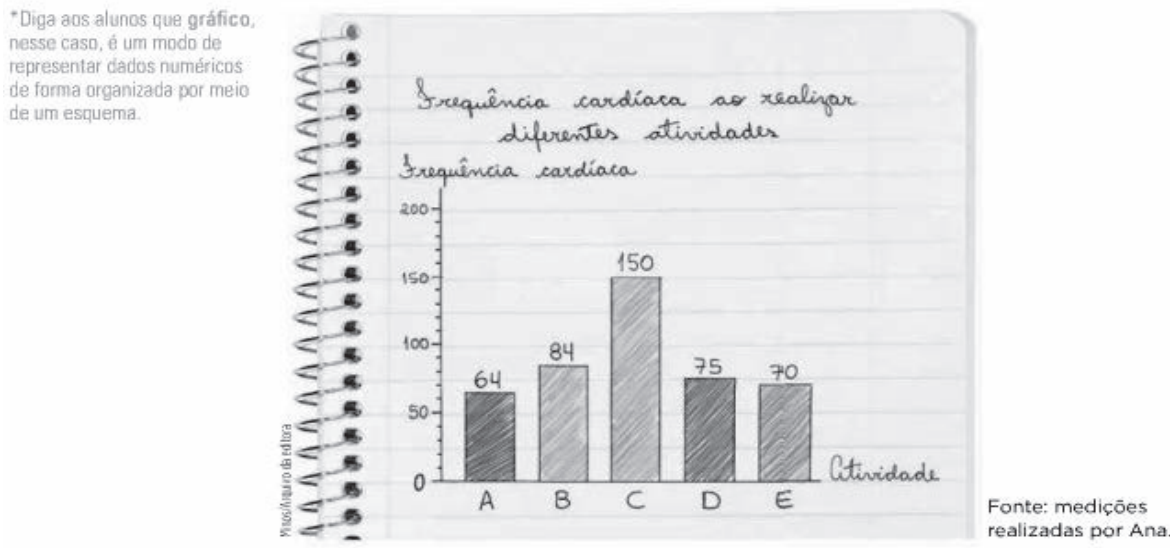

a ) O que você percebeu ao comparar a frequência cardíaca de Ana ao realizar cada atividade? Resposta esperada: a frequência cardiaca de Ana varia de acardo conn a atividade que

Fonte: A escola é nossa (Editora Scipione, 2013, p. 43)

No gráfico de colunas da Figura 2, as cores dispostas e os dados contidos no eixo das abscissas, com fonte em caixa alta, podem convidar o aluno a realizar inferências, cabendo, por exemplo, a associação das letras alfabéticas, por exemplo, ao contexto da escola.

Se esse mesmo gráfico for analisado por um sujeito com maior experiência vivida, e num outro contexto social, o eixo das abscissas, a título de exemplificação, poderá lembrá-lo a "algo relativo à escola", a algo que fez parte de sua vivência remotamente. Ou seja, cada leitor com seus conhecimentos guardados inicia uma leitura com propósitos, tais como: constatar ou refutar hipóteses, de acordo com suas previsões.

E, com a finalidade essencial, que é a compreensão do que é lido, compete ao sujeito criar suas próprias estratégias de aprendizagem, que são constantemente (re)inventadas pelo aluno segundo as suas necessidades, as suas preferências e, principalmente, de acordo com o gênero a que se dedica o estudo, tal como pontua Kleiman:

De fato, a forma do texto determina, até certo ponto, os objetivos de leitura: há um grande número de tipos de textos, como romances, contos, fábulas, biografias, notícias, ou artigos de jornal, artigos científicos, ensaios, editoriais, manuais didáticos, receitas, cartas: parece claro que o objetivo geral ao ler o jornal é diferente daquele quando lemos um artigo científico. Por exemplo, na leitura de um jornal já na primeira página o leitor faz uso de mecanismos para a apreensão rápida de informação visual dando uma mera passada de olhos (processo este chamado de "scanning" ou avistada) geralmente a fim de depreender o tema dos diversos itens a partir das manchetes. (KLEIMAN, 2000, p. 33)

$7>$ Vale ressaltar que "a velocidade leitora depende do nível de dificuldade que o material de leitura apresenta para a pessoa e, ainda, da finalidade da leitura" (ALLIENDE, 1987, p. 181).
Na leitura de gráficos, então, podemos enumerar as seguintes habilidades metacognitivas:

1. Buscar o sentido global do gráfico por meio de uma leitura seletiva espontânea (ALLIENDE, 1987, p. 178). Conhecida também como Skimming, essa estratégia de leitura propicia ao leitor encontrar informações específicas de maneira rápida ${ }^{7}$; 
2. Ler antes o gráfico do que o enunciado, para obter informações mais rapidamente: o aluno, dependendo do que motivou a leitura, tende a recorrer principalmente às colunas, quando o gráfico for de coluna; aos setores, quando o gráfico for de setores; às imagens, quando tratar-se de pictogramas, e assim sucessivamente;

3. Com o intuito de responder às questões propostas nos livros didáticos, o aluno utiliza como estratégia o ato de memorizar parte da pergunta, a que contém o propósito principal. Ou seja, ele se detém, sobretudo, no objetivo primordial do questionamento. $\mathrm{O}$ estudante procura no gráfico a priori aquilo que considerou relevante;

4. Em gráficos pictóricos ${ }^{8}$ que contêm questões referentes ao cotidiano com o qual se identifica o leitor, este diligenciará sua resposta de acordo com o conhecimento que tem acerca da imagem. Dessa maneira, a maior parte da interpretação realizada pelo leitor será mediada pelos conhecimentos ativados pela imagem. E, é válido ressaltar que esse fato não é evidente apenas com os infográficos; mesmo que o gráfico esteja somente acompanhado por alguma ilustração, o sujeito tende a partir dessa imagem para compreensão da situação exposta.

As estratégias aqui apresentadas, que possivelmente são utilizadas por leitores para a compreensão, principalmente, de textos gráficos, estão concentradas, basicamente, em dois momentos: antes e durante a leitura, deixando a desejar uma reflexão que extrapole os sentidos do texto.

Na sala de aula, portanto, a pedagogia para a compreensão leitora não deve restringirse à busca de informações no texto, mas estender-se ao (re)pensar, ao (re)avaliar dos resultados em consonância com as demais áreas e vivências (extra)acadêmicas do sujeito, ou seja, ao momento após a leitura. Pensando nisso, adiante, proporemos uma abordagem do gráfico que contemple seu caráter dialógico e que, consecutivamente, promova cidadãos críticos.

\section{A compreensão textual do gráfico enquanto ferramenta interdisciplinar e dialógica}

Na perspectiva da sala de aula, enquanto "[...] o único lugar onde as crianças podem ser colocadas quietas nos seus cantos com um livro na mão para aprender que ler é um diálogo solitário com um texto que vai se desvelando ao seu olhar" (NEVES, 2007, p.19), e na perspectiva do professor enquanto mediador e propulsor de conhecimentos, cabe a este profissional oportunizar o contato e o diálogo do aluno com as inúmeras informações presentes nos diversificados textos que emergem à comunidade cultural; para tanto, é imprescindível que seja despertado o prazer no ato de ler, tal como afirma Guedes (2007, p. 19):

\footnotetext{
Nós, professores de todas as áreas, em vez de nos limitarmos a choramingar que nossos alunos não têm o hábito da leitura, devemos nos dedicar a proporcionar muitas e muitas oportunidades para que todos descubram que ler é uma atividade muito interessante, que a leitura nos proporciona prazer, diversão, enfim. E essas oportunidades terão de ser tantas quantas forem necessárias para que o aluno passe a gostar de ler e, por isso, contraia a necessidade da leitura e que esta vire hábito. (GUEDES, 1998, p. 15 apud NEVES et al., 2007, p. 19)
}

Então, os conhecimentos obtidos por meio de inúmeras leituras não torna o sujeito capaz de lidar com as variadas situações a que está exposto. Não basta somente ter informações fragmentadas acerca das diferentes disciplinas escolares, é necessário articulá-las, para que sejam úteis a todos os domínios sociais. À soma dessa articulação entre os conhecimentos, utilizaremos a denominação de inteligência geral. Segundo Morin (2003, p. 22), é ela que permite que os problemas especiais sejam resolvidos.
$8>$ "[...] Ler um texto pictórico é adentrar em suas formas, linhas, cores, volumes e peculiaridades, na tentativa de desvelar um código milenar que muitas vezes não está explícito, nos é desconhecido e, por vezes, nos assusta" (KEHRWALD, 2000, p. 21 apud NEVES et al., 2007, p. 26). 
Assim, salientamos que, mesmo sendo desenvolvidas e postas em prática estratégias pedagógicas que possibilitem ao aluno interpretações textuais, é necessário que deixem os alunos mostrar e estudar os textos na relação que estabelecem com as demais áreas do conhecimento, com a justificativa de que não é possível entende-los isoladamente. Noutros termos, o estudo do gráfico deve considerar não apenas os postulados da matemática, mas também as múltiplas linguagens que envolvem as outras disciplinas, quais sejam: Língua Portuguesa, Geografia, Ciências Naturais, História, abarcando, dessa maneira, as vivências do aluno fora da escola, seus conhecimentos prévios, por exemplo. Dessa maneira, podemos inferir que a eficácia na compreensão textual é possível, sobretudo, pela articulação entre conhecimentos, que tem como fundamentação a interdisciplinaridade.

Levando essas pontuações até aqui discutidas para os livros didáticos, não é tão somente o diálogo entre os conhecimentos o facilitador da compreensão leitora, mas, também, a relação entre autor e leitor, para a qual o autor deve produzir textos com vistas ao público-alvo a que se destina, e o leitor busca desvendar, compreender e reconstruir a produção textual.

Entendemos que a compreensão dos textos gráficos, por nós analisados, de modo especial, é consequência da articulação entre conhecimentos, da interdisciplinaridade. E, é justamente sob esse enfoque interdisciplinar que somos capazes de buscar, reunir e compreender as informações multifacetadas transmitidas pelos gráficos.

Então, se no ensino escolar a maior parcela dos gráficos encontra-se nos livros da disciplina de Matemática, tal como expomos com o texto gráfico 1 abaixo, devemos movimentar a educação escolar para que contemple o ensino dessa disciplina interconectando os vários conhecimentos. Sobre esse movimento da educação escolar, Klüsener afirma que:

Temos ensinado matemática de maneira a não privilegiar linguagem em suas diferentes expressões - oral, escrita, visual - mas enfatizando fundamentalmente os códigos escritos. Esse procedimento pode ser creditado à metodologia utilizada no ensino e que não tem possibilitado, via de regra, nem o desenvolvimento da linguagem em todos os seus aspectos, nem a formação de conceitos, já que vem se utilizando um vocabulário básico limitado, restritivo e específico. Esta tem sido, quem sabe, uma das causas para implementar-se a distância entre a matemática ensinada na escola e a realidade matemática vivenciada pelo nosso aluno. (KLÜSENER, 2007, p. 179).

Gráfico 1 - Percentual de gráficos localizados nos livros didáticos por disciplina escolar.

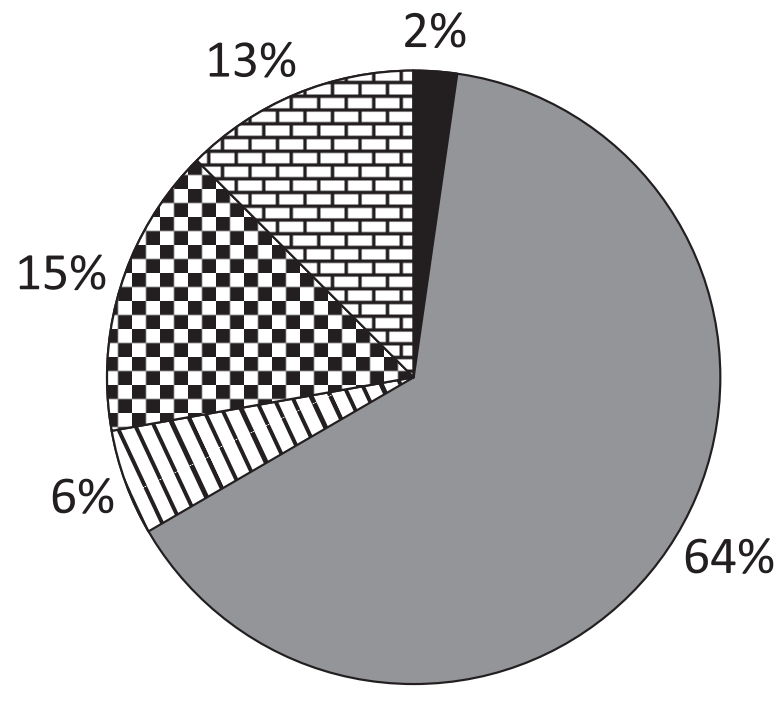

Português

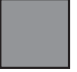

Matemática

Fonte: Elaborado pelo autor

Hístória

Geografia

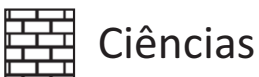


Propomos, então, a interpretação dos textos gráficos a partir dos conhecimentos pertinentes às diversas disciplinas que estão ao nosso alcance: uma análise do gráfico em sua totalidade, em busca de possíveis informações implícitas. Estudar o gráfico em consonância com fatos corriqueiros e diários proporciona ao aluno o seu encontro com o texto, despertando curiosidades diante daquilo que é familiar, interessante e útil à sua leitura de mundo.

Ao desvendar o texto em seus pormenores, possibilitamos a discussão, o questionamento, a transmissão dos dados apresentados e, consequentemente, deixamos no texto a nossa marca de leitor crítico-reflexivo. Seguindo essas proposições, analisaremos o exemplo abaixo:

Figura 3 - Projeto Buriti Multidisciplinar, Matemática, 3o ano.

(5) Observe o gráfico e responda às questões.

Uma fábrica de papel reflorestou uma área desmatada. Veja no gráfico o número de árvores plantadas em um trimestre de 2010.

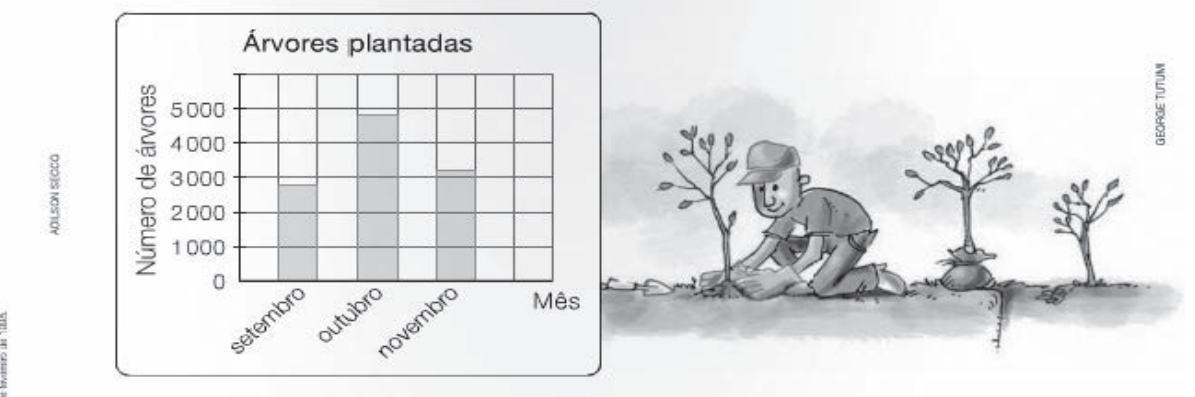

a) Nos dois primeiros meses, foram plantadas, aproximadamente,

quantas árvores ao todo?

b) No mês de dezembro de 2010 , foi plantado

o dobro do número de árvores plantadas no mês de setembro. Quantas árvores, aproximadamente,

foram plantadas em dezembro?

Fonte: Projeto Buriti Multidisciplinar (Editora Moderna, 2013, p. 192)

A questão proposta contempla discussões acerca do desmatamento e do reflorestamento, temas universais e atuais, o que pode culminar, ainda, numa pesquisa de campo na localidade da moradia dos alunos, por exemplo. Essa prática seria útil na medida em que faria com que eles vissem a realidade exposta nos livros.

Além disso, poder-se-ia fazer com que os alunos traçassem um histórico dessas atividades que vão de encontro aos cuidados para com o meio ambiente. Através dessa análise histórica, seriam obtidos dados numéricos a respeito de tais práticas, ou seja, a totalidade das áreas devastadas, tanto em termos quantitativos quanto em termos qualitativos, os prejuízos causados, os motivos que levam a essa prática etc. E, sendo o homem o principal afetado, seria viável, também, que o educador fomentasse, por exemplo, seus alunos a buscarem informações a respeito dos riscos à saúde humana.

Intercaladas a essas propostas educativas levantadas, ressaltamos a importância de atividades como: comparação entre os gráficos presentes em variados meios e suportes de comunicação (o que constatará o seu caráter interdisciplinar); levantamento das proporções que esse texto vem tomando em toda a sociedade e; estudo das múltiplas leituras que podem ser realizadas a partir de cada gráfico sondado, dentre outras inúmeras práticas educativas possíveis mediante o contato com o texto em questão.

Tornar-se um hábil leitor do mundo, capaz “[...] de enfrentar de forma inteligente textos de índole muito diversa, na maioria das vezes diferentes dos utilizados durante a instrução" (SOLÉ, 1998, p. 72), requer também, e principalmente, a habilidade na escrita, 
a citar que a proficiência na produção textual faz com que o aluno se coloque no lugar do autor, permitindo-o desautomatizar e ampliar suas habilidades e estratégias de leitura. Junto aos atos de desvendar e de (re)significar o texto, serão ampliadas a construção e a organização de informações.

\section{Autor, texto e leitor: interação e aprendizagem significativa}

Sendo a aprendizagem significativa verificada diante da "[...] leitura na qual temos controle: relendo, parando para saboreá-la ou para refletir” (SOLÉ, 1998, p. 43), em relação aos gráficos, apontamos deficiências, predominantemente, no que concerne ao convite do autor ao aluno para analisar, espontaneamente, os pormenores do texto gráfico, atribuindolhe suas impressões. No domínio da educação, buscamos, para tais textos, exatamente, a leitura que implique a significativa aprendizagem; a leitura que proporcione aos alunos saberes aplicáveis face às situações inéditas.

Os livros didáticos destinados às séries iniciais do Ensino Fundamental das escolas públicas, utilizados nesta pesquisa como objeto de estudo, oferecem-nos gráficos que contemplam o processo comunicativo, mas que, aliado ao fato de não apresentarem questões suficientes e capazes de mostrar, por si, ao aluno que os gráficos são textos dotados de conhecimentos, tem-se ainda a imagem do gráfico como quaisquer simples representações, que se subtraída não deturpa sentidos.

Os questionamentos vêm requerendo como respostas somente aquilo que já está explícito, cabendo ao aluno apenas transportar para o seu caderno as informações evidentes, sem que se tenha o prazer em realizar analogias, descobrir, questionar, ler.

Com efeito, acreditando na leitura significativa como um diálogo interacional, que tem em seu conjunto a articulação autor-texto-leitor, o autor tem papel fundamental no processo de leitura do sujeito, pois, valendo-se da palavra, ele deve ser claro e conciso o suficiente para possibilitar ao aluno seguir as pistas deixadas no texto. E o livro didático, como suporte de larga utilização na sala e como instrumento de educação, deveria oferecer subsídios ao aluno para fazê-lo ir além, para auxiliá-lo no seu crescimento como cidadão. Para Soares, a leitura

[...] não é esse ato solitário; é interação verbal entre indivíduos, e indivíduos socialmente determinados: o leitor, seu universo, seu lugar na estrutura social, suas relações com o mundo e com os outros; o autor, seu universo, seu lugar na estrutura social, suas relações com o mundo e os outros (SOARES, 2000, p. 18).

Pode-se inferir que a leitura significativa, que leva o homem a pôr em prática os seus conhecimentos, é resultado dessa interação explicada. Somente por meio da leitura consciente, em que autor e leitor estejam mediados por meio dos textos, será desenvolvida a significativa aprendizagem e será impulsionado o desenvolvimento da educação.

\section{Considerações finais}

O ponto fulcral do estudo ora apresentado foi a numerosa utilização do gráfico na/ pela sociedade global e, consecutivamente, as informações por ele propagadas. Analisado como um texto, consoante às propriedades de textualidade explicitadas, observamos as possibilidades que o estudo do gráfico apresenta para a descrição de qualquer realidade, implicando uma gama de conhecimentos originados de diferentes campos, fator que nos permitiu estudá-lo como texto interdisciplinar. 
Entendendo a compreensão do gráfico numa relação de interdependência com os vários conhecimentos que circulam na comunidade, propusemos uma didática pautada no ensino do texto gráfico mediante abordagem entre as disciplinas. Esse trabalho, realizado de modo a articular as disciplinas escolares, permite a dinamização da ação pedagógica e, principalmente, a formação de um sujeito cidadão dotado de aprendizagens e capacitado para a resolução de problemas, desde os simples aos ditos complexos.

Analisamos exemplos retirados dos livros que fazem parte do nosso corpus de pesquisa, com o caráter de demonstração da ampla discussão, capaz de ser promovida pelos textos gráficos. Discussão ampla e promissora, mas, permitida a partir do momento em que nos resgatamos na figura de um professor sabedor das propriedades que tem um gráfico, pois, se nos apoiássemos, única e exclusivamente, nos livros didáticos, aos quais creditamos serem não somente suporte às aulas, tampouco instrumento pedagógico, mas também viabilizadores de conhecimentos tal como os educadores, os resultados possivelmente não envolveriam os aspectos textuais que possuem os gráficos.

Provocamos discussões sucessivas ao que era pedido na questão, com o propósito de que fossem extraídas, qualitativamente, informações condizentes à vivência do leitor, que causassem a ele reações de ânimo, de interesse e de curiosidade para as descobertas que propiciam a leitura.

Apesar de ser pouco incidente a utilização do gráfico nos livros verificados, especialmente na disciplina de Língua Portuguesa, demonstramos que sua propriedade textual e discursiva possibilita uma interpretação mais consciente, que não seja feita somente de modo cognitivo, automático, mas que se estenda ao metacognitivo (KATO, 1995, p. 124). Nesse aspecto, prosseguimos citando algumas das habilidades que, provavelmente, são utilizadas pelo leitor na busca do entendimento do texto.

Em suma, na concepção textual do gráfico, nossas propostas referem-se, principalmente, ao tratamento atribuído pelos organizadores do livro didático ao gráfico e ao trabalho pedagógico transmitido pelo educador ao aluno. É necessário que tanto o trabalho com o livro didático quanto o profissional de qualquer que seja a disciplina escolar acompanhem os avanços relativos ao gráfico e os reconheça, explorando-os em toda a sua completude.

\section{Referências}

ALLIENDE, Felipe; CONDEMARIN, Mabel. Leitura: teoria, avaliação e desenvolvimento. In: A leitura nas diversas disciplinas. Porto Alegre: Artes médicas, 1987. p. 185-195.

BAKHTIN, Mikhail. Marxismo e filosofia da linguagem. 10. ed. São Paulo: Annablume, 2002.

. Estética da criação verbal. 4. ed. São Paulo: Martins Fontes, 2003.

DUARTE, Viviane Martins. Textos multimodais e letramento. Habilidades na leitura de gráficos da Folha de São Paulo por um grupo de alunos do ensino médio. 219p. Dissertação (Mestrado em Estudos Linguísticos) - Universidade Federal de Minas Gerais, 2008.

KATO, Mary. O aprendizado da leitura. São Paulo: Martins Fontes, 1995.

KLEIMAN, Ângela. Texto e leitor: aspectos cognitivos da leitura. 7. ed. São Paulo: Pontes, 2000.

KLÜSENER, Renita. Ler, escrever e compreender a matemática, ao invés de tropeçar nos símbolos. In: NEVES, Iara Conceição Bitencourt et al. (Orgs). Ler e escrever: compromisso de todas as áreas. Porto Alegre: UFRGS, 2007. p. 175-89.

KOCH, Ingedore Grunfeld Villaça. Desvendando os segredos do texto. 7. ed. São Paulo: Cortez, 2011.

KOCH, Ingedore Grunfeld Villaça; ELIAS, Vanda Maria. Ler e compreender os sentidos do texto. 3. ed. São Paulo: Contexto, 2012.

Ler e escrever: estratégias de produção textual. 2. ed. São Paulo: Contexto, 2012. 
LENOIR, Yves. Didática e interdisciplinaridade: uma complementaridade necessária e incontornável. In: FAZENDA, Ivani (Org.). Didática e interdisciplinaridade. São Paulo: Papirus, 1998.

MONTEIRO, Carlos Eduardo Ferreira. Interpretação de gráficos: atividade social e conteúdo de ensino. CD - 22. ANPEd, 1999.

MORIN, Edgar. A cabeça bem feita: repensar a reforma, reformar o pensamento. Tradução de Eloá Jacobina. 8. ed. Rio de Janeiro: Bertrand Brasil, 2003.

NEVES, Iara Conceição Bitencourt (Org.). Ler e escrever: compromisso de todas as áreas. Porto Alegre: Ed. UFRGS. 8. ed., 2007.

PAULA, Eunice Aparecida. Leitura e interpretação de gráficos por alunos do $5^{\circ}$ ano do ensino fundamental. Dissertação (Mestrado). UBC. Mogi das Cruzes, 2010.

PLANO Nacional de Educação. Disponível em: http://www.fnde.gov.br/index.php/pnld-guiado-livro-didatico. Acesso em: 16 nov. 2012.

ROCHA, Ruth. Minidicionário da língua Portuguesa. São Paulo: Scipione, 2005.

SMITH, Frank. Compreendendo a leitura: uma análise psicolingüística da leitura e do aprender a ler. 4. ed. Tradução de Daise Batista. Porto Alegre: Artmed, 2003.

SOARES, Magda. As condições sociais da leitura: uma reflexão em contraponto. In: ZILBERMAN, Regina; SILVA, Ezequiel Teodoro da. (Org.). Leitura: perspectivas disciplinares. São Paulo: Ed. Ática, 2000. p. 18-29.

SOLÉ, Isabel. Estratégias de leitura. Porto Alegre: Artes Médicas, 1998.

TOLEDO, Geraldo Luciano. Estatística Aplicada. 2. ed. São Paulo: Editora Atlas, 1985. 